THEORY AND METHODS

\title{
A call for reporting the relevant exposure term in air pollution case-crossover studies
}

\author{
Nino Künzli, Christian Schindler
}

J Epidemiol Community Health 2005;59:527-530. doi: 10.1136/jech.2004.027391

The exposure term in the case-crossover design consists in the difference between the ambient concentration on the event day and the concentration(s) on some control day(s). So far, all air pollution case-crossover studies presented the distribution of the daily ambient pollutant concentrations but do not publish the distributional properties of the relevant exposure term - that is, the concentration difference. This article shows that this difference can be very small for a large fraction of event days, therefore, seriously limiting the statistical power to refute the null hypothesis. Publishing the distribution of the relevant differences will improve the interpretation and discussion of findings from case-crossover studies, particularly in cases with statistically non-significant associations.

See end of article for authors' affiliations

Correspondence to: Correspondence to: School of Medicine University of Southern California, 1540 Alcazar, CHP 236, Los Angeles, CA 90033, USA; Kuenzli@ usc.edu

Accepted for publication 22 October 2004
$\mathrm{V}$ arious study designs have been used to investigate the statistical association between daily levels of air pollution and consecutive acute changes in mortality and morbidity rates. Time series studies, for example, AHPEA in Europe or NMMAPS in the USA make up the vast majority of these investigations. ${ }^{12}$ However, the case-crossover design, first described in $1991,{ }^{3}$ is a very attractive alternative approach to investigate acute effects. The design samples cases only, and effect estimates are based on the within subject comparison of exposure at failure (or event) times with exposure at control times. ${ }^{4}$ Each subject serves as their own control, leading to the benefit that stable subject specific covariates such as genetic predisposition, smoking, or other risk factors cannot confound the effect estimates. In contrast with time series studies, the case-crossover approach permits the use of individual characteristics such as age, sex, health status, or lifestyle factors to assess effects of air pollution among potentially susceptible subgroups or to explore modification of air pollution effects by individual characteristics. ${ }^{56}$

More than 20 ambient air pollution studies have adopted the case-crossover design for clinical events or death ${ }^{6-26}$ and others have discussed methodological aspects of the application. ${ }^{27-33}$ None of the studies, however, published information on the distribution of the relevant exposure term-that is, the concentration differences between event and control days. In this paper, we show that the distribution of these differences is an important missing characteristic for the evaluation of power, the interpretation of findings, and the comparison across studies. For a broader discussion of strengths and limitations of the case-crossover design we refer the interested reader to a recent review of this approach in air pollution epidemiology ${ }^{5}$ and the above mentioned methodological papers.

\section{THE RELEVANT EXPOSURE TERM IN CASE-} CROSSOVER STUDIES IS A DIFFERENCE

In the traditional air pollution time series studies such as APHEA or NMMAPS ${ }^{34} 35$ the relevant exposure term is the daily level of some ambient air pollutants. Accordingly, these studies publish characteristics of the distribution of these concentrations such as the mean, interquartile, or total range. Keeping all other factors constant, it may be argued that effects are more easily estimated in a city with a wide range across daily concentrations. However, only the short term component of this variation is actually relevant for the power of this type of statistical analysis whereas long term and seasonal fluctuations in air pollutant concentrations are filtered out by the trend and seasonal variables incorporated in the respective models.

The case-crossover design compares ambient air pollutant concentrations at or shortly before an event-for example, a cardiac arrest ${ }^{17}$ —with concentrations on a control day, using conditional logistic regression. (As usual in air pollution epidemiology, ambient concentrations are used as a surrogate measure or indicators of exposure whereas true personal exposure to pollution from ambient origin is not known. To reflect the use of an indicator of exposure, we set "exposure" in quotes). Under the null hypothesis, "exposure" on control days should not be different from "exposure" at (or shortly before) the event. Control days are selected in various ways, most often 7,14 , or 21 days before and/or after the event, to control for time varying cofactors that might be associated with day of the week. Bias is reduced if control days are selected bi-directionally, considering the mean concentrations on the days $k$ weeks before and after the event (anterior and posterior controls, respectively) as the "control exposure", where $k$ commonly equals $1,2,3$, or $4 .{ }^{31}$ As usual in epidemiological studies, the distribution of the exposure term (that is, in our case the concentration difference between event and control days) is a driving force of statistical power. If ambient air pollution has a true effect on the event probability, the null hypothesis can only be rejected if the nature of the ambient air pollution time series is such that the difference between event and control days shows sufficient variation 
around a non-zero mean value. For example, if ambient concentrations show very little variability between event and control days, this leads to similar "exposure" levels in the two periods, thus limiting the power to detect effects. The more variable these concentration differences are, the higher the power to detect a true association (see appendix, available on the journal web site http://www.jech.com/supplemental).

So far, none of the air pollution case-crossover studies published the distributional properties of this exposure term (that is, the difference in "exposure" between event and control days). To show the importance of distinguishing between this relevant exposure term and the absolute daily levels of pollutants we use pollution data from three communities. Formal results regarding statistical power in the case-crossover and the Poisson time series design are given in the appendix (available on line http://www.jech. com/supplemental).

\section{METHODS AND RESULTS}

Table 1 lists the "exposure" distribution as typically provided in case-crossover air pollution studies. We only show those studies with sample sizes (that is, number of events) up to 1000 and studies with non-significant findings. However, similar information can be found in all publications.

To show the distinction between the distribution of daily mean concentrations-relevant in time series studies-and the distribution of the concentration differences between "event" and "control" days-relevant for case-crossover studies-we used daily nitrogen dioxide $\left(\mathrm{NO}_{2}\right)$ data from three Swiss locations.

We chose the 1999-2000 daily fixed site monitor data from a rather clean alpine community, Davos, the city of Basle in the more populated area of the upper Rhine, and the city of Lugano in the southern part of Switzerland with the highest concentrations. These three communities belong to the SAPALDIA study, and daily $\mathrm{NO}_{2}$ data were easily available. ${ }^{36}$ However, the choice of the pollutant is not relevant for our purposes, and the conclusions apply to all exposure terms used in case-crossover studies.

The first part of table 2 shows the distributional characteristics of these daily ambient $\mathrm{NO}_{2}$ concentrations as usually provided in time series analyses and case-crossover studies. The second part of the table presents the distribution of the exposure term that would be relevant if you were to conduct a case-crossover study in these communities.

In this hypothetical example, we assume that events may occur every day ("event" days). We further assume a bidirectional approach. The relevant term of daily "exposure" was therefore calculated as the difference between the concentration on the respective day and the average concentration over the two "control" days, chosen seven days before and after (bidirectional), as done in some studies. ${ }^{12} 20$

In Davos, on $75 \%$ of the days (or events), the "control" values differ by less than $7.7 \mu \mathrm{g} / \mathrm{m}^{3}$ from those of the corresponding "event" days. For half of all days, event and control "exposure" will differ by less than $2.8 \mu \mathrm{g} / \mathrm{m}^{3}$, whereas the interquartile range of daily $\mathrm{NO}_{2}$ values is $13 \mu \mathrm{g} / \mathrm{m}^{3}$. Moreover, 90\% of "exposure" differences do not exceed $17.1 \mu \mathrm{g} / \mathrm{m}^{3}$, whereas the $80 \%$ range of daily concentrations is $29 \mu \mathrm{g} / \mathrm{m}^{3}$. Restriction of the time series to summer periods, where fluctuations in $\mathrm{NO}_{2}$ tend to be lower, further decreases the expected contrast between "event" and "control" concentrations with $90 \%$ of differences not exceeding $5.2 \mu \mathrm{g} / \mathrm{m}^{3}$ (last part of table 2 ).

\section{DISCUSSION}

We have shown that the exposure term relevant in casecrossover studies can have rather narrow distributions, therefore statistical power (see appendix) may be jeopardised. The distribution of the difference between concentrations on "event" and "control" days-the only relevant exposure term in the case-crossover design-needs to be presented. The distribution of the daily concentrations does not reveal this relevant information. In fact, the daily concentrations usually spread over much broader ranges. Thus focusing on that distribution in the planning and evaluation of case-crossover studies is misleading. As shown in the appendix, the variation of concentration differences rather than of absolute levels determines the statistical power of this type of analysis.

Comparing tables 1 and 2 (first part) shows that the cities chosen in our hypothetical example have ranges in the pollution levels comparable to those reported in many casecrossover studies. The spread (for example, 10th to 90th centile) is similar in the Swiss cities (that is, 29 to $40 \mu \mathrm{g} / \mathrm{m} 3$ ) and slightly lower in Seattle, but higher in Boston and Kaohsiung. Therefore, we consider the Swiss examples a reasonable model.

As shown in these data, the nature of the pollution time series can be such that for a large number of potential "event" days concentrations would be very similar to those on the days chosen as controls. Adjustment for seasonal and weather factors, as usually done, would most probably further reduce the contrast between "event" and "control" exposure terms. In this case, the ability to observe a statistical difference between event and control days is substantially reduced and effect estimates tend to be driven by events occurring during the winter period or a few influential eventcontrol "exposure" pairs. In summary, power to detect a statistically significant effect of ambient air pollution is a priori low if short term variability of exposure is small.

The power calculation in the appendix shows that sample size, as usual, is an important element. As case-crossover studies in contrast with time series analyses often involve rather small samples, for example, a few hundred events $^{11} 13141725$ statistical power is further reduced. A prior assessment of the distribution of the relevant exposure term and its impact on power would lead investigators to strategies

Table 1 Distribution of daily concentrations (24 hour mean) of ambient air pollutants as published in case-crossover studies. Only studies with no significant associations or with sample size (number of events) $<1000$ are listed

\begin{tabular}{|c|c|c|c|c|c|c|c|c|c|c|}
\hline City & $\begin{array}{l}\text { Number of } \\
\text { events }\end{array}$ & $\begin{array}{l}\text { Pollutant } \\
\left(\mu \mathrm{g} / \mathrm{m}^{3}\right)\end{array}$ & Mean & Min & $10^{\text {th }}$ & 25th & 50 th & 75th & 90th & $\operatorname{Max}$ \\
\hline Seattle, USA, Sullivan et a ${ }^{17}$ & 1062 & PM10 & 28.1 & 7.4 & N/A & 18.0 & 24.8 & 35.1 & 45.6 & 89.8 \\
\hline Seattle, USA, Levy et al ${ }^{13}$ & 362 & PM2.5 & 18.4 & 1.0 & 7.5 & 10.0 & 15.5 & 23.0 & 33.0 & 96.0 \\
\hline $\begin{array}{l}\text { Kaohsiung, Taiwan, } \\
\text { Tsai et al }\end{array}$ & $>35000$ & $\mathrm{NO}_{2}^{*}$ & 54.0 & 8.5 & N/A & 36.5 & 54.3 & 70.2 & N/A & 119.8 \\
\hline Boston, USA, Peters et $a l^{14}$ & 722 & $\mathrm{NO}_{2}{ }^{*}$ & 45.4 & N/A & $20.8+$ & N/A & 41.6 & N/A & $73.7 \dagger$ & N/A \\
\hline Boutin-Forzano et $a l^{25}$ & 549 & $\mathrm{NO}_{2} \ddagger$ & 34.9 & 3.0 & N/A & N/A & N/A & N/A & N/A & 85.8 \\
\hline Rich et $\left.a\right|^{26}$ & $<100$ & $\mathrm{NO}_{2} \S$ & 16.5 & $\mathrm{~N} / \mathrm{A}$ & $\mathrm{N} / \mathrm{A}$ & IQR 5.4 & N/A & $\mathrm{N} / \mathrm{A}$ & $\mathrm{N} / \mathrm{A}$ & N/A \\
\hline
\end{tabular}

${ }^{*} 1 \mathrm{ppb}$ assumed to be $1.89 \mu \mathrm{g} / \mathrm{m} 3$. $† 5$ th and 95 th centiles, respectively. $\mathrm{N} / \mathrm{A}$, not published. $\ddagger$ Results were also shown for $\mathrm{SO}_{2}$ and $\mathrm{O}_{3}$ (statistically significant only for $\mathrm{O}_{3}$ ). §Results also shown for several other pollutants. None were statistically significant. 
Table 2 Distribution of the absolute differences between the daily levels of $\mathrm{NO}_{2}$ ("event days") and the average concentrations over the two "control days" (for example, seven days before and after) using data from 1999 and 2000 . All units are in $\mu \mathrm{g} / \mathrm{m}^{3}$

\begin{tabular}{|c|c|c|c|c|c|c|}
\hline City & Mean & 10th & 25 th & 50 th & $75 \mathrm{th}^{\mathrm{h}}$ & 90th \\
\hline \multicolumn{7}{|c|}{ (1) Distribution of daily concentrations of $\mathrm{NO}_{2}$} \\
\hline Davos & 14.1 & 4.4 & 5.5 & 8.6 & 18.4 & 33.4 \\
\hline Basle & 25.4 & 10.3 & 15.8 & 23.4 & 32.8 & 42.8 \\
\hline Lugano & 38.3 & 20.0 & 25.5 & 35.4 & 48.6 & 60.0 \\
\hline \multirow{2}{*}{\multicolumn{7}{|c|}{$\begin{array}{l}\text { (2) Distribution of the absolute differences between daily concentrations of } \mathrm{NO}_{2} \text { and the average concentrations of } \mathrm{NO}_{2} \text { over the two control days (that is, } \\
\pm 7 \text { days } \\
\text { Full two year data }\end{array}$}} \\
\hline & & & & & & \\
\hline Davos & 6.2 & 0.5 & 1.2 & 2.8 & 7.7 & 17.1 \\
\hline Basle & 9.9 & 1.4 & 3.8 & 8.2 & 13.6 & 21.0 \\
\hline Lugano & 10.2 & 1.3 & 3.4 & 7.1 & 13.1 & 25.0 \\
\hline \multicolumn{7}{|c|}{ Summer months only (April to October) } \\
\hline Davos & 2.3 & 0.3 & 0.8 & 1.7 & 2.9 & 5.2 \\
\hline Basle & 7.1 & 1.0 & 2.7 & 5.9 & 10.3 & 15.3 \\
\hline Lugano & 6.8 & 0.9 & 2.6 & 5.4 & 9.0 & 14.2 \\
\hline
\end{tabular}

aiming at increasing the event sample size. For example, the distribution of $\mathrm{NO}_{2}$ concentration differences in Davos is so narrow that you would either need a very large number of events or choose a different location to set up a case-crossover study with sufficient statistical power to detect, for example, an effect of air pollution on mortality. The studies from Seattle, Taiwan, and Vancouver, and also some studies from France $^{13} 17202526$ have comparatively small samples. In all theses cases, "exposure" on case and control days might not have differed enough to warrant sufficient statistical power for detecting existing effects. Based on the published data of one study it seems that in Vancouver the range of daily concentrations was even smaller than in our example from Davos. The IQR of $\mathrm{NO}_{2}$ was only $5.4 \mu \mathrm{g} / \mathrm{m}^{3}$ in Vancouver compared with about $13 \mu \mathrm{g} / \mathrm{m}^{3}$ in Davos. The range of the relevant exposure term might have been extremely small in this study that relied on less than 100 events. ${ }^{26}$ In case of the Seattle studies, the reported distribution of daily PM values (table 1) suggests that daily variability of air pollution was comparable to the one seen in Davos (table 2).

Our three examples show that the exposure conditions would be more favourable if you were to conduct a casecrossover study in the city of Basle or Lugano where differences can be expected to be roughly two to three times (summer) as large as in Davos. The respective information is not provided in any case-crossover study and cannot be inferred from table 1 data. In fact, the distribution of the difference depends on the choice of the lag between event and control days, the day to day variability, and thus, ultimately, on prevailing weather and emission patterns, which may differ across regions, seasons, and/or over time.

In light of null findings, a rigorous discussion of power is required (see appendix). Data presented in the format of table 1 permit only speculation that power was insufficient in some studies. Presentation of data in the format of table 2

\section{What this paper adds}

- It is good epidemiological practice to publish the exposure distribution. So far, air pollution case-crossover studies have neither reported nor discussed the exposure term relevant for this design.

- This paper emphasises the potential lack of power in case-crossover studies. It makes a strong case for full disclosure of the relevant exposure information.

\section{Policy implications}

It is important to distinguish "no effects" from a lack of statistical power to detect existing effects. The proposition to publish the relevant exposure information increases an understanding of this distinction. This leads to appropriate interpretations of research findings on acute effects of ambient air pollution that ultimately frame policies.

(second part) would show whether the size of the difference is small for a large fraction of days or not.

The need to investigate and publish the relevant exposure term is also amplified in case-crossover studies comparing associations for a set of pollutants or providing multipollutant models. Multi-pollutant models ${ }^{913}{ }^{16}$ are often used to investigate the varying contribution of specific pollutants or sources. The ability to disentangle pollutant effects depends on their correlation. However, in the case-crossover study the correlation between concentration differences rather than across absolute concentration values is of relevance and should therefore be reported. In fact, correlation patterns of absolute daily levels are likely to be distinct from those of the concentration differences relevant in the case-crossover design. In addition, the issue is important in the evaluation and control of other covariates, for example, weather factors. Here, again, the relevant correlation is the one between concurrent differences and not the one between concurrent absolute daily values.

Given that the daily level of ambient air pollution is not the exposure term relevant for case-crossover studies, it is misleading to report associations, as done in many papers, for the interquartile range of this measure. Estimates for different pollutants will be comparable only if presented for the interquartile range of the relevant exposure term-that is, the concentration difference between "event" and "control" days.

\section{CONCLUSION}

Reporting of the relevant study specific "exposure" data (table 2) will permit the comparison of results across studies, for meta-analyses of comparable studies to be conducted, the advancement of our understanding of results, and the improvement in the ability to decide which null findings may have resulted from a lack of power. Future studies should aim at the statistical power necessary for detecting true effects and for determining whether variation in these 
effects may reflect geographical differences in the toxicity of pollutants or in the susceptibility of populations. Thus, we strongly recommend that case-crossover studies investigate and publish the distributional properties of the difference between "event" and "control" exposure and the correlation of this measure between pollutants. The mere distribution of daily values does not disclose relevant properties of the concentration difference between event and control days.

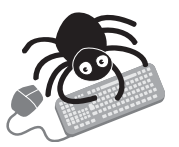

The appendix giving details of the power calculations for the case-crossover model and for the Poisson regression model is available on the journal web site (http://www.jech.com/supplemental).

\section{Authors' affiliations}

N Künzli, Keck School of Medicine University of Southern California, Department of Preventive Medicine, Division of Occupational and Environmental Health, Los Angeles, USA

C Schindler, Institute of Social and Preventive Medicine, University Basle, Switzerland

Funding: Professor Kuenzli is supported by the Southern California Environmental Health Sciences Center (National Institute of Environmental Health Sciences grant P30 ESO7048) and the Hastings Foundation.

Conflicts of interest: none declared.

\section{REFERENCES}

1 Katsouyanni K, Touloumi G, Spix C, et al. Short-term effects of ambient sulphur dioxide and particulate matter on mortality in 12 European cities: results from time series data from the APHEA project. Air Pollution and Health: a European Approach, BMJ 1997;314:1658-63.

2 Samet JM, Dominici F, Curriero FC, et al. Fine particulate air pollution and mortality in 20 US cities, 1987-1994. N Engl J Med 2000;343:1742-9.

3 Maclure $M$. The case-crossover design: A method for studying transient effects on the risk of acute events. Am J Epidemiol 1991;133:144-53.

4 Navidi W, Weinhandl E. Risk set sampling for case-crossover designs. Epidemiology 2002;13:100-5.

5 Jaakkola JJ. Case-crossover design in air pollution epidemiology. Eur Respir J Suppl 2003:40:81-5s.

6 Bateson TFSJ. Who is sensitive to the effects of particulate air pollution on mortality? A case-crossover analysis of effect modifiers. Epidemiology 2004; 15:131-2.

7 Lee JT, Schwartz J. Reanalysis of the effects of air pollution on daily mortality in Seoul, Korea: a case-crossover design. Environ Health Perspect 1999; 107:633-6.

8 Neas LM, Schwartz J, Dockery D. A case-crossover analysis of air pollution and mortality in Philadelphia. Environ Health Perspect 1999;107:629-31.

9 Kwon HJ, Cho SH, Nyberg F, et al. Effects of ambient air pollution on daily mortality in a cohort of patients with congestive heart failure. Epidemiology 2001;12:413-19.

10 Sunyer J, Schwartz J, Tobias A, et al. Patients with chronic obstructive pulmonary disease are at increased risk of death associated with urban particle air pollution: a case- crossover analysis. Am J Epidemiol 2000;151:50-6.

11 Sunyer J, Basagana X, Belmonte J, et al. Effect of nitrogen dioxide and ozone on the risk of dying in patients with severe asthma. Thorax 2002;57:687-93.

12 Sunyer J, Basagana X. Particles, and not gases, are associated with the risk of death in patients with chronic obstructive pulmonary disease. Int J Epidemiol $2001 ; 30: 1138-40$.
13 Levy $\mathrm{D}$, Sheppard L, Checkoway $\mathrm{H}$, et al. A case-crossover analysis of particulate matter air pollution and out-of-hospital primary cardiac arrest. Epidemiology 2001;12:193-9.

14 Peters A, Dockery DW, Muller JE, et al. Increased particulate air pollution and the triggering of myocardial infarction. Circulation 2001;103:2810-15.

15 Lin $M$, Chen Y, Burnett RT, et al. The influence of ambient coarse particulate matter on asthma hospitalization in children: case-crossover and time-series analyses. Environ Health Perspect 2002;110:575-81.

16 Kan HCB. A case-crossover analysis of air pollution and daily mortality in Shanghai. J Occup Health 2003;45:1 19-24.

17 Sullivan J, Ishikawa N, Sheppard L, et al. Exposure to ambient fine particulate matter and primary cardiac arrest among persons with and without clinically recognized heart disease. Am J Epidemiol 2003;157:501-9.

18 D'Ippoliti DFF, Ancona C, Agabiti Fusco D, et al. Air pollution and myocardial infarction in Rome. A case-crossover analysis. Epidemiology 2003; 14:528-35.

19 Lin M, Chen Y, Burnett RT, et al. Effect of short-term exposure to gaseous pollution on asthma hospitalisation in children: a bi-directional case-crossover analysis. J Epidemiol Community Health 2003;57:50-5.

20 Tsai SS, Huang CH, Goggins WB, et al. Relationship between air pollution and daily mortality in a tropical city: Kaohsiung, Taiwan. J Toxicol Environ Health A 2003;66:1341-9.

21 Tsai SS, Goggins WB, Chiu HF, et al. Evidence for an association between air pollution and daily stroke admissions in Kaohsiung, Taiwan. Stroke 2003;34:2612-16.

22 Schwartz J. Is the association of airborne particles with daily deaths confounded by gaseous air pollutants: an approach to control by matching. Env Health Perspect 2004.

23 Yang CCCC, Chuang HY, Tsai SS, et al. Relationship between air pollution and daily mortality in a subtropical city: Taipei, Taiwan. Environ Int 2004;30:519-23.

24 Yang CCYS, Yang CH, Ho SC. Relationship between ambient air pollution and hospital admissions for cardiovascular diseases in Kaohsiung, Taiwan. J Toxicol Environ Health 2004;67:483-93.

25 Boutin-Forzano S, Adel N, Gratecos L, et al. Visits to the emergency room for asthma attacks and short-term variations in air pollution. A case-crossover study. Respiration 2004;71:134-7.

26 Rich K, Petkau J, Vedal S, et al. A case-crossover analysis of particulate air pollution and cardiac arrhythmia in patients with implantable cardioverter defibrillators. Inhal Toxicol 2004; 16:363-72.

27 Bateson TF, Schwartz J. Selection bias and confounding in case-crossover analyses of environmental time-series data. Epidemiology 2001;12:654-61.

28 Bateson TF, Schwartz J. Control for seasonal variation and time trend in casecrossover studies of acute effects of environmental exposures. Epidemiology 1999; 10:539-44

29 Sheppard L, Levy D, Checkoway H. Correcting for the effects of location and atmospheric conditions on air pollution exposures in a case-crossover study. J Expo Anal Environ Epidemiol 2001;11:86-96.

30 Levy D, Lumley T, Sheppard L, et al. Referent selection in case-crossover analyses of acute health effects of air pollution. Epidemiology $2001 ; 12: 186-92$

31 Lee JT, Kim H, Schwartz J. Bidirectional case-crossover studies of air pollution: bias from skewed and incomplete waves. Environ Health Perspect 2000;108:1107-11

32 Navidi W, Thomas D, Langholz B, et al. Statistical methods for epidemiologic studies of the health effects of air pollution. Res Rep Health Eff Inst 1999: 1-50.

33 Fung KY, Krewski D, Chen Y, et al. Comparison of time series and casecrossover analyses of air pollution and hospital admission data. Int J Epidemiol 2003;32:1064-70.

34 Katsouyanni K, Touloumi G, Spix C. Short-term effects of ambient sulphur dioxide and particulate matter on mortality in 12 European cities: results from times series data from the APHEA project. BMJ 1997;314:1658-63.

35 Samet JM, Zeger SL, Dominici F, et al. The national morbidity, mortality, and air pollution study. Part II: morbidity and mortality from air pollution in the United States. Res Rep Health Eff Inst 2000;94:5-70

36 Martin BW, Ackermann-Liebrich U, Leuenberger P, et al. SAPALDIA: methods and participation in the cross-sectional part of the Swiss study on air pollution and lung diseases in adults. Soz Praventivmed 1997;42:67-84. 